\title{
Value sensitive design as a formative framework
}

\author{
David G. Hendry ${ }^{1}\left[\right.$ ] Batya Friedman ${ }^{1} \cdot$ Stephanie Ballard ${ }^{1}$
}

Accepted: 13 January 2021 / Published online: 26 February 2021

(c) The Author(s) 2021

\begin{abstract}
In this article, we first offer a model of design knowledge types (know-about, know-that, know-how) and their interrelationships in value sensitive design. Then we demonstrate that value sensitive design is a formative framework, which provides a shaping influence on practice, enables creative appropriation, and supports theory and method development.
\end{abstract}

Keywords Design knowledge $\cdot$ Design method $\cdot$ Design model $\cdot$ Design theory $\cdot$ Formative framework $\cdot$ Skillful practice $\cdot$ Value sensitive design

While value sensitive design can be considered to be many things-a perspective for exploring the human-technology relationship, a theory of design, a methodology, a set of design tools, a community of practice, a field of research-it is surely a design framework. When employing value sensitive design in projects, designers bring together conceptual, empirical, and technical investigations (e.g., Friedman 2004; Davis and Nathan 2014; Friedman et al. 2017; Friedman and Hendry 2019). The process unfolds in a manner that is responsive to the design situation. By systematically accounting for human values during design, tools and technologies can be designed that lead to greater good and lesser harm (for a thorough discussion of this central motivating proposition of value sensitive design, see Van den Hoven 2013).

Given this dynamic unfolding, what kind of design framework is value sensitive design? We engage this question, first, to clarify the possibilities for taking up, appropriating, and extending value sensitive design and, second, to take a step toward developing a critical vocabulary for examining varied approaches to technology, human values, and design.

David G. Hendry

dhendry@uw.edu

Batya Friedman

batya@uw.edu

Stephanie Ballard

ballard4@uw.edu

1 The Value Sensitive Design Lab, The Information School, University of Washington, Mary Gates Hall, Suite 370,

Box 352840, Seattle, WA 98195-2840, USA
We shall see that value sensitive design is a formative framework (Rasmussen 1997; Vicente 1999), a framework that bounds and guides design processes. It frames and nudges, prompting designers to attend to value-oriented aspects of design situations and to pursue certain kinds of work. In short, value sensitive design places a distinctive shaping influence on designers. Formative frameworks differ in purpose from prescriptive ones, which prescribe that certain steps be followed to frame a design problem and to arrive at a solution. The IEEE P7000 standard, under development at the time of writing, is an example of a prescriptive framework because specific methods for considering moral and ethical concerns are embedded within a waterfall model for software development (IEEE Standards Association 2016; see also Spiekermann 2015). Formative frameworks also differ in purpose from descriptive frameworks, which describe how design processes unfold and the practices and skills of designers and other participating stakeholders. One example of a descriptive framework can be found in value levers (Shilton 2012), which document and describe common aspects of design situations that cause designers to pause and reflect on values and issues of ethical import. ${ }^{1}$

\footnotetext{
$\overline{1 \text { Descriptive, }}$ prescriptive, and formative design frameworks are each valuable on their own terms, and might be complementary in purpose. For example, in the service of improving value sensitive design's formative framework descriptive studies of value sensitive design in practice could help to identify misunderstandings, innovative appropriation, and new opportunities for theory and method development.
} 


\section{A model of design knowledge in value sensitive design}

To clarify the dynamics of value sensitive design and uncover its formative structure, we present the following model which distinguishes three types of design knowledge-know-about (theory), know-that (translation), and know-how (method) - and their interrelationships (see Fig. 1 and Table 1). Within each knowledge type and with an eye toward enacting design, we further identify relevant knowledge elements. We then consider how these knowledge types and elements work together as a formative framework.

Intended to be an working expository sketch, this model is consistent with authoritative accounts (Friedman 2004; Davis and Nathan 2014; Friedman et al. 2017; Friedman and Hendry 2019). As with other design perspectives (Pye 1978; Winograd and Flores 1986; Schön 1987; Nelson and Stolterman 2012), value sensitive design integrates theoretical and practical knowledge, with each responsive to the design situation. By theoretical knowledge we mean broad, general concepts that are widely applicable across particular design situations. By practical knowledge we mean design skill, intuition, experience, judgement, and wisdom, characteristic of master craftsmen and reflective practitioners. While the model surely raises new questions-for example, what are the forms of practical, theoretical, and translational knowledge; how do these forms of knowledge integrate and support mutually deep inquiry; how are heuristics related to theory and methods; how are project-specific theory-to-practice commitments formed, and so forth-its aim is to present illustrative knowledge types of value sensitive design and their interrelationships, concisely and comprehensibility. Given our primary purpose, namely to demonstrate how value sensitive design is a formative framework, in Table 1 in addition to the three knowledge types, we include six exemplary knowledge elements.

\section{Beginning with theory}

The theoretical constructs, the foundation of value sensitive design, are well-chosen abstractions, propositions or perspectives, carefully defined and explicated for considering design situations - the know-about knowledge that needs to be engaged. Distilled from the philosophical, social science, and technical literatures and informed by practical experience, the theoretical constructs characterize how values are implicated in design processes. To illustrate, one theoretical construct demarcates the distinction between direct stakeholders, those who interact directly with a technology under consideration, and indirect stakeholders, those who

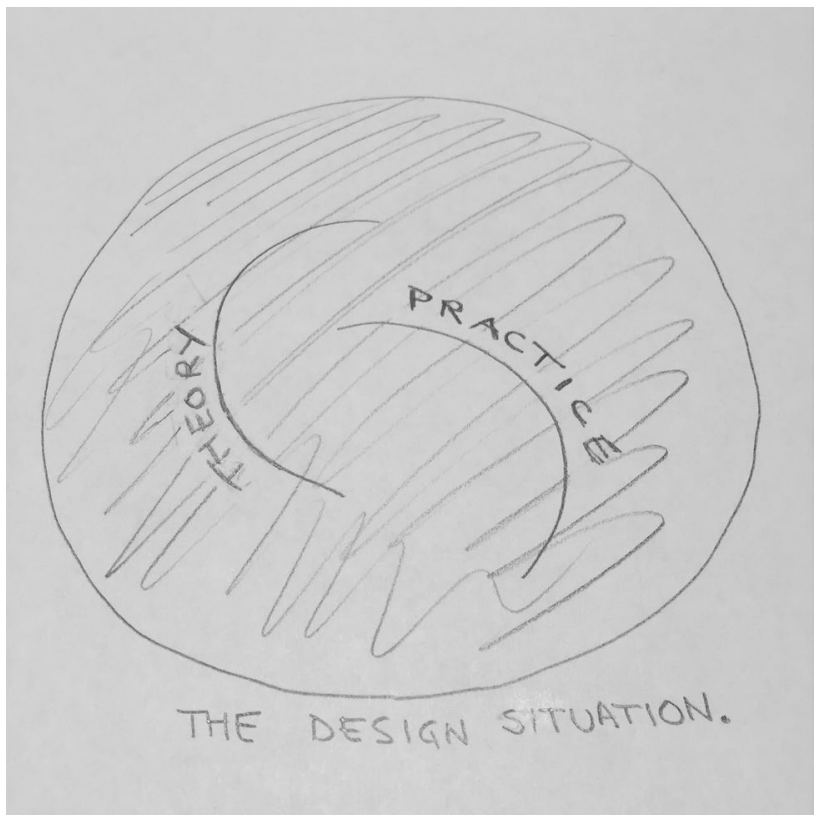

Fig. 1 Through translational processes, theory and practice mutually inform and shape each other; each responsive to the design situation

are more broadly affected by the technology. As societies evolve, as literature and discourse develops, and as value sensitive design projects are completed and reflected upon, the theoretical constructs develop too. Current discussion of systemic racism in the United States, for example, leads to consideration of stakeholders not only by role (e.g., direct and indirect stakeholder) but also by individual or community identity. Similarly, developing discussions worldwide of the moral standing of non-human beings (e.g., clams, wolves, rivers, mountains, stars) leads to consideration of non-human stakeholders and associated theory.

\section{Next is translation}

The theory-to-practice commitments are framing and shaping constraints that aid in translation, that guide designers in planning their design processes and unfolding work. Metaphorically, theory-to-practice commitments are analogous to: a grammar that represents a language but not particular sentences; a morphological analysis of a class of objects but no single object; or a social policy that is intended to lead to desired ends but does not stipulate specific means. Theory-to-practice commitments, simply put, translate the theoretical constructs into action-oriented statements for moving forward. Responsive to the design situation, these commitments are largely declarative. They embody know-that (what needs attending to) but not know-how (the skills, intuitions, and knowledge of practical action) (Ryle 1945-1946; Schön 1987, p. 22). For example, following the 
Table 1 Model of types of design knowledge and their interrelationships in value sensitive design, with (reading from bottom to top) theory providing a foundation for contextualized, in situ practice. Trans- lational processes operate in both directions, from theory-to-practice and from practice-to-theory

\begin{tabular}{|c|c|c|c|c|}
\hline & $\begin{array}{c}\text { Knowledge } \\
\text { Element }\end{array}$ & $\begin{array}{c}\text { Definition } \\
\text { of Element }\end{array}$ & $\begin{array}{c}\text { Knowledge } \\
\text { Type }\end{array}$ & Example \\
\hline \multirow{3}{*}{ Practice } & Heuristic & $\begin{array}{l}\text { Guidance for selecting, } \\
\text { ordering, and managing } \\
\text { value-oriented design } \\
\text { processes }\end{array}$ & Know-how & $\begin{array}{l}\text { - Conduct stakeholder } \\
\text { analysis early } \\
\text { - Prioritize which } \\
\text { stakeholders to emphasize } \\
\text { and which to set aside } \\
\text { given resource constraints }\end{array}$ \\
\hline & Method & $\begin{array}{l}\text { Focused activity } \\
\text { intended to uncover or } \\
\text { develop particular kinds } \\
\text { of value-oriented design } \\
\text { insights or directions }\end{array}$ & Know-how & $\begin{array}{l}\text {-Direct and indirect } \\
\text { stakeholder analysis } \\
\text {-Stakeholder tokens }\end{array}$ \\
\hline & Toolkit & $\begin{array}{l}\text { Physical and digital } \\
\text { materials that support } \\
\text { value sensitive design } \\
\text { investigations and } \\
\text { methods }\end{array}$ & Know-how & $\begin{array}{l}\text { The "stakeholder" cards in } \\
\text { the Envisioning Cards } \\
\text { toolkit }\end{array}$ \\
\hline \multirow{2}{*}{ Translation } & $\begin{array}{l}\text { Practice-to-Theory } \\
\text { Commitment }\end{array}$ & $\begin{array}{l}\text { Delineated empirical } \\
\text { accounts from practice } \\
\text { that translate into } \\
\text { specific refinements, } \\
\text { extensions or additions } \\
\text { to the theoretical } \\
\text { constructs and directs } \\
\text { innovation in theory }\end{array}$ & Know-that & $\begin{array}{l}\text { Stakeholders who hold to } \\
\text { individual or community } \\
\text { identity provide empirical } \\
\text { insights and reasons to } \\
\text { broaden the theoretical } \\
\text { construct of stakeholders to } \\
\text { account for identity in } \\
\text { addition to role }\end{array}$ \\
\hline & $\begin{array}{l}\text { Theory-to-Practice } \\
\text { Commitment }\end{array}$ & $\begin{array}{l}\text { Declarative statements } \\
\text { that translate the } \\
\text { theoretical constructs } \\
\text { into actionable value- } \\
\text { oriented project steps or } \\
\text { design processes }\end{array}$ & Know-that & $\begin{array}{l}\text { Interests of direct and } \\
\text { indirect stakeholders must } \\
\text { be addressed }\end{array}$ \\
\hline Theory & $\begin{array}{l}\text { Theoretical } \\
\text { Construct }\end{array}$ & $\begin{array}{l}\text { Abstractions, } \\
\text { propositions, or } \\
\text { perspectives, carefully } \\
\text { defined and explicated } \\
\text { for value-oriented } \\
\text { framing and } \\
\text { consideration of design } \\
\text { situations }\end{array}$ & Know-about & $\begin{array}{l}\text { Direct and indirect } \\
\text { stakeholders are impacted } \\
\text { by technology }\end{array}$ \\
\hline
\end{tabular}


theoretical construct distinguishing between direct and indirect stakeholders, the theory-to-practice commitment is to legitimate both direct and indirect stakeholders and bring their interests, including an analysis of potential harms and benefits, into the design process. However, exactly how to engage with direct and indirect stakeholders is left to other knowledge elements. As a matter of generally expected practice, the theory-to-practice commitments have a normative quality, establishing a firm point of view for guiding action without prescribing particular procedures or checklists.

\section{Now to practice}

(We shall return to the practice-to-theory commitment shortly.) The heuristics, methods, and toolkits are knowledge elements that represent some aspects of skillful practice. Notably, there could be many more here. In contrast to the theoretical constructs and theory-to-practice commitments, the heuristics, methods, and toolkits focus on know-how, that is, taking action and doing things in the design situation.

To select and employ a toolkit or method well means to be faithful to the theory-to-practice commitments. Being faithful does not refer to some kind of easily recognized conformance. Instead, it means a genuine critical engagement with the commitments, seeking to explicate their meaning and use, or perhaps non-use. Thus, for example, to identify and to legitimate the direct and indirect stakeholders in a design project, many different toolkits or empirical or analytic methods might be employed, depending on the design situation. Two examples are the Envisioning Cards toolkit with its stakeholder card suit and the stakeholder tokens method (Yoo 2018; Friedman and Hendry 2019).

Complementing methods and toolkits, to support design practice are heuristics. Specifically, heuristics emphasize strategies and nuance to be applied in and across methods and toolkits. Among other things, heuristics are useful in planning, and for considering how to adjust design processes as the design situation is engaged. For example, "To get started on a new project, it is often useful to conduct a conceptual analysis of direct and indirect stakeholders." Heuristics arise largely from reflections on skillful practice, during or after projects, along with studies of projects reported in the literature, conversations with designers, and so on.

\section{Returning to translation}

For the practice-to-theory commitment, taking action in the design situation-through empirical, technical or conceptual investigations - will likely lead to unexpected findings and new insights. The practice-to-theory knowledge element marks the shaping influence of situated, practical experience on theory. Given a routine or at least fairly well-understood design situation, the particulars of design work will readily fit within existing theory as, for example, would be the case of identifying a new indirect-stakeholder role. However, in other cases, empirical data or other design work will stretch existing theory or problematize it. In such cases, a gap in theory might be exposed which, in turn, offers opportunities for refining or extending existing theoretical constructs or for inventing new ones. For example, the development of new policies, laws or social norms related to identity have pointed to limitations with stakeholder analyses based solely on roles. Generally, to maintain the integrity of the theoretical foundation, changes or additions to theory are narrow, targeted and made judiciously.

\section{Stepping back}

Value sensitive design, in its entirety, is directed toward taking action in "design situations" (Nelson and Stolterman 2012; Schön 1987), typically characterized ecologically, by complexity and uncertainty, and comprising all the cultural, environmental, legal, political, social, and technical elements that bear on or support design. Skillful practice, seen broadly as drawing on experience, artistry, and wisdom, infuses the entire model.

\section{Value sensitive design as a formative framework}

With this model in hand, we now return to our question: What kind of framework is value sensitive design? And to our response: A formative one. The term "formative" emphasizes a certain kind of influence on skillful practice, namely a guiding or shaping influence within bounds, with flexible constraints and without prescriptions. As we have seen, the translational theory-to-practice and practice-to-theory commitments embody this shaping influence by nudging designers toward certain kinds of framings and modes of inquiry; so too with the heuristics, methods and toolkits. But no rigid step-by-step procedures are prescribed - the sequence of actions is left up to the designers as they engage with the design situation, including stakeholders.

One benefit of the formative influence of the value sensitive design framework is that it positions designers to be sensitive to values, noting that sensitive refers to a designer who is engaging with values in the full complexity of the design situation and who is seeking good overall solutions, not perfect ones. Relatedly, because the value sensitive design framework does not represent design procedurally, with specified inputs and outputs at each step, it lends itself to creative appropriation, no matter the application domain. This flexibility, however, does come with added opportunity and responsibility. 
Another benefit of the formative structure is that value sensitive design is both stable and also open to revision; it can organically absorb expansion, adjustment and adaptation. In particular, the separation of the theoretical constructs from the translational commitments offers the framework stability and integrity while enabling ongoing development. For example, new and original theory-to-practice commitments might be derived from the theoretical constructs. Or, specialized theory-to-practice commitments related to a particular project might be developed. Or, a theoretical construct might be problematized in a practice-to-theory commitment and further developed. In each case, this work can be done without destabilizing the overall integrity of the framework.

\section{Conclusion}

In summary, we have demonstrated that, like a compass which offers a reliable orientation for moving forward in vaguely understood terrain, value sensitive design is a dependable framework for design situations, which are typically complex and uncertain. Key to understanding the formative dynamics of value sensitive design are the knowledge types, their interrelationships, and their shaping influence. Recall that the purpose of Table 1 is to make some working distinctions so as to clarify how value sensitive design is a formative framework. That said, ultimately, we think of value sensitive design as part art and part science with rich intricacy that currently defies full expression. As a counterpoint to the precision of Table 1, recall Fig. 1 which conveys the ineffable integration of theory and practice. Inquiry into the knowledge of design, and specifically the knowledge of value sensitive design, is a continuing opportunity, indeed, a grand challenge.

Of many directions for further inquiry, one immediate implication concerns theory-to-practice commitments: What theory-to-practice commitments, even if implicitly, are regularly used in value sensitive design projects? How, if at all, do designers develop such commitments, particularize them for design situations, and link them to the theoretical constructs? How do these commitments come to shape design processes? In a different vein, this model might be helpful for learning about value sensitive design, as it provides a guide for reading authoritative accounts or for scrutinizing research papers. We would expect such inquiry to lead to elaboration and expansion of the model.

Looking to the future, one way to further develop value sensitive design would be to identify useful concepts about the framework itself, that is, meta-concepts. The idea that value sensitive design is a formative framework is one such meta-concept. Once identified and explicated, meta-concepts might be used to investigate the characteristics and merits of different approaches to technology, human values, and design.

Lastly, we observe: To be useful, a design approach needs to strike a meaningful balance between openness and specificity. An approach that is too open leaves designers with insufficient practical guidance for which type of design knowledge (know-about, know-that, and know-how) to apply, and when and how to apply it. An approach that is too specific runs the risk of prescribing design actions that do not adequately account for the unique realities of each design situation and, in turn, might result in designs that ultimately do more harm than good. Value sensitive design has long sought such a robust, sensitive balance.

Acknowledgements Our sincere thanks to Jason Millar for stimulating discussion and written comments and to the reviewers whose careful reading and comments helped us improve this article.

Open Access This article is licensed under a Creative Commons Attribution 4.0 International License, which permits use, sharing, adaptation, distribution and reproduction in any medium or format, as long as you give appropriate credit to the original author(s) and the source, provide a link to the Creative Commons licence, and indicate if changes were made. The images or other third party material in this article are included in the article's Creative Commons licence, unless indicated otherwise in a credit line to the material. If material is not included in the article's Creative Commons licence and your intended use is not permitted by statutory regulation or exceeds the permitted use, you will need to obtain permission directly from the copyright holder. To view a copy of this licence, visit http://creativecommons.org/licenses/by/4.0/.

\section{References}

Davis, J., \& Nathan, L. P. (2014). Value sensitive design: Applications, adaptations, and critiques. In J. van den Hoven, P. E. Vermaas, \& I. van de Poel (Eds.), Handbook of ethics, values, and technological design (pp. 1-26). New York: Springer.

Friedman, B., Hendry, D. G., \& Borning, A. (2017). A survey of value sensitive design methods. Foundations and Trends in HumanComputer Interaction, 11(23), 63-125.

Friedman, B., \& Hendry, D. G. (2019). Value sensitive design: Shaping technology with moral imagination. Cambridge, MA: MIT Press.

Friedman, B. (2004). Value sensitive design. In W. S. Bainbridge (Ed.), Berkshire encyclopedia of human-computer interaction (pp. 769 774). Great Barrington, MA: Berkshire Publishing Group.

Hoven, J. van den (2013). Value sensitive design and responsible innovation. In R. Owen, J. Bessant, \& M. Heintz (Eds.), Responsible innovation (pp. 75-83). Hoboken, NJ: John Wiley \& Sons.

IEEE Standards Association. (2016). P7000 - model process for addressing ethical concerns during system design. Retrieved from http://standards.ieee.org/develop/project/7000.html.

Nelson, H. G., \& Stolterman, E. (2012). The design way: Intentional change in an unpredictable world (2nd ed.). Cambridge, MA: The MIT Press.

Pye, D. (1978). The nature and aesthetics of design. London: The Herbert Press.

Rasmussen, J. (1997). Merging paradigms: Decision making, management, and cognitive control. In R. Flin, E. Salas, M. Strub, \& L. Mai (Eds.), Decision making under stress: Emerging themes and applications (pp. 67-81). Brookfield, VT: Ashgate. 
Ryle, G. (1945-1946). Knowing how and knowing that: The presidential address. Proceedings of the Aristotelian Society, 1945-1946, $46,1-16$

Schön, D. A. (1987). Educating the reflective practitioner: Toward a new design for teaching and learning in the professions. San Francisco, CA: Jossey-Bass.

Shilton, K. (2012). Value levers: Building ethics into design. Science, Technology, \& Human Values, 38(3), 374-397.

Spiekermann, S. (2015). Ethical IT innovation: A value-based system design approach. Boca Raton, FL: Auerbach Publications.

Vicente, K. (1999). Cognitive work analysis: Toward safe, productive, and healthy computer-based work. New York: Taylor \& Francis.
Winograd, T., \& Flores, F. (1986). Understanding computers and cognition: A new foundation for design. Boston: Addison-Wesley.

Yoo, D. (2018). Stakeholder Tokens: A constructive method for value sensitive design stakeholder analysis. Ethics and Information Technology. https://doi.org/10.1007/s 1067 6-018-9474-4.

Publisher's Note Springer Nature remains neutral with regard to jurisdictional claims in published maps and institutional affiliations. 